\title{
Identification of clinically relevant viridans streptococci by analysis of transfer DNA intergenic spacer length polymorphism
}

\author{
Y. De Gheldre, ${ }^{1}$ P. Vandamme, ${ }^{2,3}$ H. Goossens ${ }^{3}$ and M. J. Struelens
}

Author for correspondence: Yves De Gheldre. Tel: +32 2555 4517. Fax: + 3225556459. e-mail: ydegheld@ulb.ac.be

1 Department of

Microbiology, Hôpital

Erasme, Université Libre de

Bruxelles, 808 Route de

Lennik, 1070 Brussels,

Belgium

2 Laboratory of

Microbiology and

BCCM/LMG Culture

Collection, University of

Ghent, Belgium

3 Laboratory of Medical Microbiology, University Hospital Antwerp. Antwerp, Belgium
The utility of PCR analysis of transfer DNA intergenic spacer length polymorphism (tDNA-ILP) for the identification to the species level of clinically relevant viridans streptococci was evaluated with a collection of reference strains of 15 species of the salivarius, anginosus, mitis and mutans rRNA homology groups. PCR products generated by using fluorescent, outwardly directed, consensus tDNA primers were analysed by electrophoresis on denaturating polyacrylamide gels and by laser fluorescence scanning. Eleven species showed specific and distinct tDNA patterns: Streptococcus cristatus, Streptococcus gordonii, Streptococcus oralis, Streptococcus mitis, Streptococcus pneumoniae, Streptococcus sanguinis, Streptococcus parasanguinis, Streptococcus anginosus, Streptococcus mutans, Streptococcus criceti and Streptococcus ratti. Indistinguishable patterns were obtained among two groups of species: Streptococcus vestibularis and Streptococcus salivarius on the one hand and Streptococcus constellatus and Streptococcus intermedius on the other. S. mitis strains produced heterogeneous patterns that could be separated into three groups: a group containing $S$. mitis biovar 1 and two S. mitis biovar 2 groups, one of which clustered with S. parasanguinis strains while the other showed patterns unrelated to other species. These results agree in part with protein electrophoretic analysis showing that $S$. mitis biovar 2 strains belong to several streptococcal taxa. In conclusion, PCR analysis of tDNA-ILP holds promise for rapid identification of viridans streptococci that are difficult to identify by phenotypic tests.

Keywords: viridans streptococci, transfer DNA intergenic spacer length polymorphism analysis, genotypic identification

\section{INTRODUCTION}

The viridans streptococci currently encompass 20 species, which are commensal inhabitants of the oropharyngeal cavity and the gastrointestinal and genital tracts of mammals (Hardie \& Whiley, 1994). On the basis of 16S rRNA sequence homology, these bacteria are categorized in four groups: the salivarius rRNA homology group, including Streptococcus thermophilus, Streptococcus vestibularis and Streptococcus salivarius; the mitis group, including Streptococcus cristatus, Streptococcus gordonii, Streptococcus oralis, Streptococcus mitis, Streptococcus pneumoniae,

Abbreviation: tDNA-ILP, transfer DNA intergenic spacer length polymorphism.
Streptococcus sanguinis and Streptococcus parasanguinis; the anginosus group, including Streptococcus anginosus, Streptococcus constellatus and Streptococcus intermedius; and the mutans group, including Streptococcus mutans, Streptococcus criceti, Streptococcus downei, Streptococcus ferus, Streptococcus macacae, Streptococcus ratti and Streptococcus sobrinus (Hardie \& Whiley, 1994; Bentley et al., 1991; Kawamura et al., 1995). In this study, we focused on the 15 species that are described as facultative pathogens in humans, causing a variety of infections including abscesses, bacteraemia, endocarditis and meningitis. Consequently, $S$. thermophilus, $S$. downei, $S$. ferus and $S$. macacae, which to our knowledge were not isolated from humans, and $S$. sobrinus, which is rarely reported in human infections, were not included. 


\section{Table 1. Bacterial strains and tDNA-ILP patterns}

Culture collections are abbreviated as follows: ATCC, American Type Culture Collection, Manassas, VA, USA; CCUG, Culture Collection University of Göteborg, Department of Clinical Bacteriology, Göteborg, Sweden; CDC, Centers for Disease Prevention and Control, Atlanta, GA, USA; LHMC, Department of Oral Microbiology, Royal London Hospital Medical College, London, UK; LMG, BCCM/LMG Culture Collection, Laboratorium voor Microbiologie Gent, Universiteit Gent, Belgium; NCFB, National Collection of Food Bacteria, Institute of Food Research, Reading Laboratory, Reading, UK; NMH, M. W. D. Wen, North Middlesex Hospital, London, UK. The tDNA-ILP types are as shown in Fig. 4.

\begin{tabular}{|c|c|c|c|c|c|c|}
\hline \multirow[t]{2}{*}{ Species } & \multirow[t]{2}{*}{ Strain } & \multirow[t]{2}{*}{ Other strain numbers } & \multirow[t]{2}{*}{ Reference } & \multirow[t]{2}{*}{ Strain isolation } & \multicolumn{2}{|c|}{ tDNA-ILP type } \\
\hline & & & & & $\begin{array}{c}\text { Visual } \\
\text { comparison }\end{array}$ & $\begin{array}{l}\text { Pearson } \\
\text { coefficient } \\
\text { comparison }\end{array}$ \\
\hline \multicolumn{7}{|l|}{ Salivarius group } \\
\hline \multirow{4}{*}{ S. salivarius } & LMG $11489^{\mathrm{T}}$ & NCFB $1779^{\mathrm{T}}$, CCUG $17825^{\mathrm{T}}$ & Whiley \& Hardie (1988) & Human blood & 9 & $\mathbf{I}$ \\
\hline & LMG 13103 & NCFB 1777 & & Unknown & 9 & I \\
\hline & LMG 13107 & NCFB 2700 , strain M36 & Whiley \& Hardie (1988) & Unknown & 9 & I \\
\hline & LMG 13108 & NCFB 2701, strain A385 & & Unknown & 9 & I \\
\hline \multirow[t]{4}{*}{ S. vestibularis } & LMG $13516^{\mathrm{T}}$ & CCUG $24893^{\mathrm{T}}, \mathrm{MM} 1^{\mathrm{T}}$, NCTC $12166^{\mathrm{T}}$ & Whiley \& Hardie (1988) & Human vestibular mucosa & 9 & I \\
\hline & LMG 14647 & CCUG 24686, LV81, Carlsson87 & Whiley \& Hardie (1988) & Human vestibular mucosa & 9 & I \\
\hline & LMG 14645 & CCUG 24684, LV71, Carlsson85 & Whiley \& Hardie (1988) & Human vestibular mucosa & 9 & I \\
\hline & LMG 14646 & CCUG 24685, PV91, Carlsson86 & Whiley \& Hardie (1988) & Human vestibular mucosa & 9 & I \\
\hline \multicolumn{7}{|l|}{ Anginosus group } \\
\hline \multirow[t]{5}{*}{ S. anginosus } & LMG $14502^{\mathrm{T}}$ & CCUG $27298^{\mathrm{T}}$, NCTC $10713^{\mathrm{T}}$ & Whiley \& Hardie (1988) & Throat & 2 & B \\
\hline & LMG 14696 & CCUG 223, NCTC 8037 & Whiley \& Hardie (1988) & Respiratory tract & 2 & B \\
\hline & LMG 17666 & CCUG 28191, LHMC PC4890 & Whiley \& Hardie (1988) & Dental plaque & 2 & B \\
\hline & LMG 17832 & CCUG 28192 , LHMC NMH10 & Whiley \& Hardie (1988) & Perforated ulcer & 2 & B \\
\hline & LMG 17833 & CCUG 28195, CDC 2236-81 & Whiley \& Hardie (1988) & Human blood & 2 & B \\
\hline \multirow[t]{5}{*}{ S. constellatus } & LMG 14503 & CCUG 4215, NCTC 5389 & Whiley \& Hardie (1988) & Unknown & 1 & A \\
\hline & LMG 14504 & CCUG 9569, NCTC 10708 & Whiley \& Hardie (1988) & Dental abscess & 1 & A \\
\hline & LMG $14507^{T}$ & CCUG $24889^{\mathrm{T}}$, NCFB $2226^{\mathrm{T}}$ & Whiley \& Hardie (1988) & Purulent pleurisy & 1 & A \\
\hline & LMG 17665 & CCUG 28196, LHMC AM699 & Whiley \& Hardie (1988) & Dental plaque & 1 & A \\
\hline & LMG 17835 & CCUG 28197, LHMC NMHI & Whiley \& Hardie (1988) & Brain abscess & 1 & $A$ \\
\hline \multirow[t]{4}{*}{$S$. intermedius } & LMG 14548 & CCUG 28203, LHMC NMH2 & Whiley \& Hardie (1988) & Brain abscess & 1 & A \\
\hline & LMG 14549 & CCUG 28204, LHMC GN72 & Whiley \& Hardie (1988) & Unknown & 1 & A \\
\hline & LMG 14550 & CCUG 28205, LHMC AC4817 & Whiley \& Hardie (1988) & Dental plaque & 1 & A \\
\hline & LMG $17840^{\mathrm{T}}$ & CCUG $17827^{\mathrm{T}}, \mathrm{NCFB} 2227^{\mathrm{T}}$ & Whiley \& Hardie (1988) & Unknown & 1 & A \\
\hline Mitis group & & & & & & \\
\hline S. cristatus & LMG 14512 & CCUG 30424, LHMC AK1 & Handley et al. (1991) & Throat swab & 8 & $\mathrm{H}$ \\
\hline & LMG $16320^{\mathrm{T}}$ & CCUG $33481^{\mathrm{T}}$, CR $311^{\mathrm{T}}$ & Handley et al. (1991) & Periodontal abscess & 8 & $\mathrm{H}$ \\
\hline & LMG 17206 & LHMC CCSA & Handley et al. (1991) & Dental plaque & 8 & $\mathrm{H}$ \\
\hline & LMG 17207 & LHMC CR3 & Handley et al. (1991) & Dental plaque & 8 & $\mathrm{H}$ \\
\hline & LMG 17842 & & & Human blood & 8 & $\mathrm{H}$ \\
\hline S. gordonii & LMG 14515 & CCUG 4216, NCTC 10231, SK5 & Kilian et al. (1989) & (biovar 2) & 4 & $\mathrm{D}$ \\
\hline & LMG 14516 & CCUG 18734 , NCTC 3165 , SK 51 & Kilian et ai. (1989) & (biovar 3) & 4 & $\mathrm{D}$ \\
\hline & LMG 14517 & CCUG 25607, SK 6 & Kilian et al. (1989) & (biovar 1) & 4 & $\mathrm{D}$ \\
\hline & LMG $14518^{\mathrm{T}}$ & CCUG $25608^{\mathrm{T}}, \mathrm{SK}^{\mathrm{T}}$ & Kilian et al. (1989) & Endocarditis (biovar 2) & 4 & $\mathrm{D}$ \\
\hline & LMG 17844 & CCUG 25510, Carlsson 31 & Carlsson (1968) & Human oral cavity & 4 & $\mathrm{D}$ \\
\hline S. oralis & LMG $14532^{\mathrm{T}}$ & CCUG $24891^{\mathrm{T}}, \mathrm{SK} 23^{\mathrm{T}}$ & Kilian et al. (1989) & Human oral cavity & 11 & $\mathrm{~K}$ \\
\hline & LMG 14533 & CCUG 24892, SK2, ATCC 10557 & Kilian et al. (1989) & Endocarditis & 11 & $\mathrm{~K}$ \\
\hline & LMG 14534 & CCUG 27680, Carlsson 50 & Carlsson (1968) & Human oral cavity & 11 & $\mathrm{~K}$ \\
\hline & LMG 14535 & CCUG 27681, Carlsson51 & Carlsson (1968) & Human oral cavity & 11 & $\mathrm{~K}$ \\
\hline & LMG 14536 & CCUG 27682, Carlsson39 & Carlsson (1968) & Human oral cavity & 11 & $\mathrm{~K}$ \\
\hline S. sanguinis & LMG 14637 & CCUG 25606, SK 45 & Kilian et al. (1989) & Human dental plaque (biovar 4) & 7 & $\mathrm{G}$ \\
\hline & LMG 14638 & CCUG 27744, SK 72 & Kilian et al. (1989) & Human dental plaque (biovar 1) & 7 & $\mathrm{G}$ \\
\hline & LMG 14639 & CCUG 27745, SK 77 & Kilian et al. (1989) & Human dental plaque (biovar 1 ) & 7 & $\mathrm{G}$ \\
\hline & LMG 14656 & CCUG 25604, SK 164 & Kilian et al. (1989) & Human dental plaque (biovar 2) & 7 & G \\
\hline & LMG 14657 & CCUG 25605, SK 150 & Kilian et al. (1989) & Human dental plaque (biovar 3 ) & 7 & G \\
\hline & LMG $14702^{\mathrm{T}}$ & CCUG $17286^{\mathrm{T}}$, ATCC $10556^{\mathrm{T}}, \mathrm{SK} 1^{\mathrm{T}}$ & Kilian et al. (1989) & Endocarditis (biovar 1) & 7 & G \\
\hline S. mitis & LMG 14554 & CCUG 27740, SK 135 & Kilian et al. (1989) & Human oral cavity (biovar 1) & 10 & $\mathrm{~J}$ \\
\hline & LMG 14555 & CCUG 27741, SK 138 & Kilian et al. (1989) & Human dental plaque (biovar 1 ) & 10 & $\mathrm{~J}$ \\
\hline & LMG $14557^{\mathrm{T}}$ & CCUG $31611^{\mathrm{T}}$, NCTC $12261^{\mathrm{T}}$, SK $142^{\mathrm{T}}$ & Kilian et al. (1989) & Human oral cavity (biovar 1) & 10 & J \\
\hline & LMG 14553 & CCUG 25611, SK 34 & Kilian et al. (1989) & Human oral cavity (biovar 2 ) & 12 & $\mathrm{~L}$ \\
\hline & LMG 14556 & CCUG 27743, SK 79 & Kilian et al. (1989) & Human oral cavity (biovar 2) & 12 & $\mathrm{~L}$ \\
\hline & LMG 17594 & CCUG 27742, SK 71 & Kilian et al. (1989) & Human oral cavity (biovar 2) & 14 & $\bar{M}$ \\
\hline & LMG 17595 & CCUG 21026, SK 132 & Kilian et al. (1989) & Ulcerated sore throat (biovar 2) & 13 & $\mathbf{M}$ \\
\hline & LMG 17596 & CCUG 35789, SK96 & Kilian et al. (1989) & Human oral cavity (biovar 2) & 12 & $\mathrm{~L}$ \\
\hline S. parasanguinis & LMG $14537^{\mathrm{T}}$ & 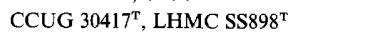 & Whiley \& Hardie (1988) & Throat & 13 & $\mathbf{M}$ \\
\hline & LMG 14538 & CCUG 30418, LHMC SS897 & Whiley \& Hardie (1988) & Throat & 13 & M \\
\hline & LMG 14540 & CCUG 30420, LHMC 3156-81 & Whiley \& Hardie (1988) & Blood & 13 & $\mathbf{M}$ \\
\hline & LMG 17852 & CCUG 30423, LHMC MGH 413 & Whiley \& Hardie (1988) & Urine & 13 & M \\
\hline S. pneumoniae & LMG 14542 & CCUG 2839A & & Human blood & 6 & $\mathbf{F}$ \\
\hline & ATCC 6301 & & & & 6 & $\mathrm{~F}$ \\
\hline & LMG 14544 & CCUG 10708 & & Acute otitis & 5 & $\mathrm{E}$ \\
\hline & ATCC 49619 & & Jorgensen et al. (1992) & Sputum & 5 & $\mathrm{E}$ \\
\hline & ATCC 49620 & & & Sputum & 5 & $\mathbf{E}$ \\
\hline
\end{tabular}


Table 1 (cont.)

\begin{tabular}{|c|c|c|c|c|c|c|}
\hline \multirow[t]{2}{*}{ Species } & \multirow[t]{2}{*}{ Strain } & \multirow[t]{2}{*}{ Other strain numbers } & \multirow[t]{2}{*}{ Reference } & \multirow[t]{2}{*}{ Strain isolation } & \multicolumn{2}{|c|}{ tDNA-ILP type } \\
\hline & & & & & $\begin{array}{c}\text { Visual } \\
\text { comparison }\end{array}$ & $\begin{array}{l}\text { Pearson } \\
\text { coefficient } \\
\text { comparison }\end{array}$ \\
\hline \multicolumn{7}{|c|}{ Mutans group } \\
\hline \multirow[t]{2}{*}{ S. mutans } & LMG $14558^{\mathrm{T}}$ & CCUG $11877^{\mathrm{T}}$, NCTC $10449^{\mathrm{T}}$ & Coykendall (1977) & Human decayed tooth & 3 & $\mathrm{C}$ \\
\hline & LMG 14560 & CCUG 32092 & & Human blood, endocarditis & 3 & $\mathrm{C}$ \\
\hline \multirow[t]{2}{*}{ S. criceti } & LMG $14508^{T}$ & CCUG $27300^{\mathrm{T}}$, NCFB $2720^{\mathrm{T}}$, strain HS6 ${ }^{\mathrm{T}}$ & Coykendall (1977) & Hamster caries lesion & 15 & $\mathrm{~N}$ \\
\hline & LMG 14511 & CCUG 28071, strain AHT & Coykendall (1977) & Human caries lesion & 15 & $\mathrm{~N}$ \\
\hline \multirow[t]{2}{*}{ S. ratti } & LMG $14650^{\mathrm{T}}$ & CCUG $27502^{\mathrm{T}}$, ATCC $19645^{\mathrm{T}}$ & Coykendall (1977) & Laboratory rat & 16 & $\mathrm{O}$ \\
\hline & LMG 14651 & CCUG 27641, strain BHT & Coykendall (1977) & Human & 16 & $\mathrm{O}$ \\
\hline
\end{tabular}

Analysis of transfer DNA intergenic spacer length polymorphism (tDNA-ILP), based on PCR amplification of spacers between tRNA genes, was proposed by McClelland et al. (1992) to distinguish streptococcal strains of groups A, B and G and $S$. mutans strains at the species level. This technique has been applied successfully to the identification of Staphylococcus (Welsh \& McClelland, 1991, 1992; Maes et al., 1997), Acinetobacter (Ehrenstein et al., 1996) and Listeria species (Vaneechoutte et al., 1998). In this study, we evaluated the discriminatory power of tDNA-ILP analysis, using laser scanning of fluorescently labelled amplicons, for identification of reference and type strains of clinically significant species of viridans streptococci. In addition, the clustering of tDNAILP patterns was compared with phylogenetic trees obtained from sequence data from 16S rRNA (Kawamura et al., 1995), superoxide dismutase (Poyart et al., 1998) and D-alanine:D-alanine ligase (Garnier et al., 1997) genes to determine its phylogenetic significance.

\section{METHODS}

Bacterial strains. Type and reference strains $(n=66)$ from the BCCM/LMG and ATCC culture collections are described in Table 1.

Preparation of DNA. Bacteria were cultured on blood-agar plates for $24 \mathrm{~h}$ at $37^{\circ} \mathrm{C}$ in an atmosphere supplemented with $10 \% \mathrm{CO}_{2}$. Genomic DNA was extracted from cells in a procedure that used sequentially lysozyme, guanidium thiocyanate, ammonium acetate, chloroform/isoamyl alcohol, 2-propanol and ethanol, as described previously (Pitcher et al., 1989).

tDNA-ILP PCR assay. PCR was carried out with the outwardly directed tDNA consensus primers T5A (5'-AGTCCGGTGCTCTAACCAACTGAG) and T3B (5'-AGGTCGCGGGTTCGAATCC) described by Welsh \& McClelland (1991). Primer T5A was 5'-end-labelled with carbocyanine dye Cy5 (Pharmacia Biotech). Fifty microlitres of PCR solution contained 1.25 U Taq polymerase (Cetus Corp), $1 \times$ PCR buffer $(50 \mathrm{mM} \mathrm{KCl}, 10 \mathrm{mM}$ Tris $/ \mathrm{HCl}, \mathrm{pH} 8 \cdot 3)$, $1.5 \mathrm{mM} \mathrm{MgCl}_{2}, 0.5 \mu \mathrm{M}$ of each primer, $0.2 \mathrm{mM}$ of the four dNTPs and $5 \mu$ l DNA extract. The reaction mixture was overlaid with a drop of mineral oil. Amplification conditions were as described previously (Welsh \& McClelland, 1991).

Analysis of tDNA-ILP. The amplification products were separated by electrophoresis through $6 \%$ (w/v) acrylamide/bisacrylamide $/ 7 \mathrm{M}$ urea denaturating gels (ReadyMix Gel, ALF grade; Pharmacia) in $1 \times$ TBE buffer. A fluorescein-labelled molecular marker (Cy5 Sizer 50-500; Pharmacia), including ten fragments ranging from 50 to $500 \mathrm{bp}$, was used as an external sizing ladder and placed in every sixth lane. Samples including $1 \cdot 25 \mu$ of the PCR products, $5 \mu \mathrm{l}$ gel-loading solution (Pharmacia) and $0.4 \mu \mathrm{l}$ each of $50 \mathrm{bp}$ and $1000 \mathrm{bp}$ internal reference standards were denatured at $100^{\circ} \mathrm{C}$ for $3 \mathrm{~min}$ and loaded onto the gel. Electrophoretic separation was done by using the ALFexpress DNA sequencer (Pharmacia) at $1500 \mathrm{~V}, 60 \mathrm{~mA}$ and $30 \mathrm{~W}$ for $4 \mathrm{~h}$ at $40^{\circ} \mathrm{C}$. Gels were normalized in two steps: by alignment firstly with external standards and then with internal standards. Fluorescence densitograms were produced by using the Fragment MANAGER software (Pharmacia) and compared visually. Digitized densitograms were exported to and analysed with the GELCOMPAR software (Applied Maths). Similarity matrices of Pearson product-moment correlation coefficients between pairs of PCR patterns were used for construction of a similarity dendrogram by using the unweighted pair group method with averages (UPGMA) algorithm.

Reproducibility evaluation. Duplicate bacterial lysates of each type strain were co-amplified in the same PCR experiment and in separate PCR experiments. These repeat samples were analysed in the same gel for between-run and between-extract pattern reproducibility. Between-gel reproducibility was assessed by analysing one amplicon ( $S$. cristatus LMG $16320^{\mathrm{T}}$ ) in three different gels. Fluorescence densitograms were compared visually and the reproducibility of normalized tDNA-ILP patterns was evaluated by using Pearson product-moment correlation coefficients.

\section{RESULTS}

\section{Reproducibility}

Between-extract, between-run and between-gel comparisons of tDNA-ILP patterns showed complete reproducibility by visual analysis of fluorescence densitograms. The number and size of DNA fragments (densitogram peak positions) were highly reproducible. Small variations occurred only in amplified product concentration (peak heights). Normalized tDNA-ILP patterns showed a mean $95 \%$ similarity coefficient (range 91-99\%) for between-extract and between-run comparisons of the 15 species. Betweengel comparison of $\mathrm{tDNA}$-ILP patterns showed a mean $94.2 \%$ similarity coefficient (range 92.9-96.3\%). On 


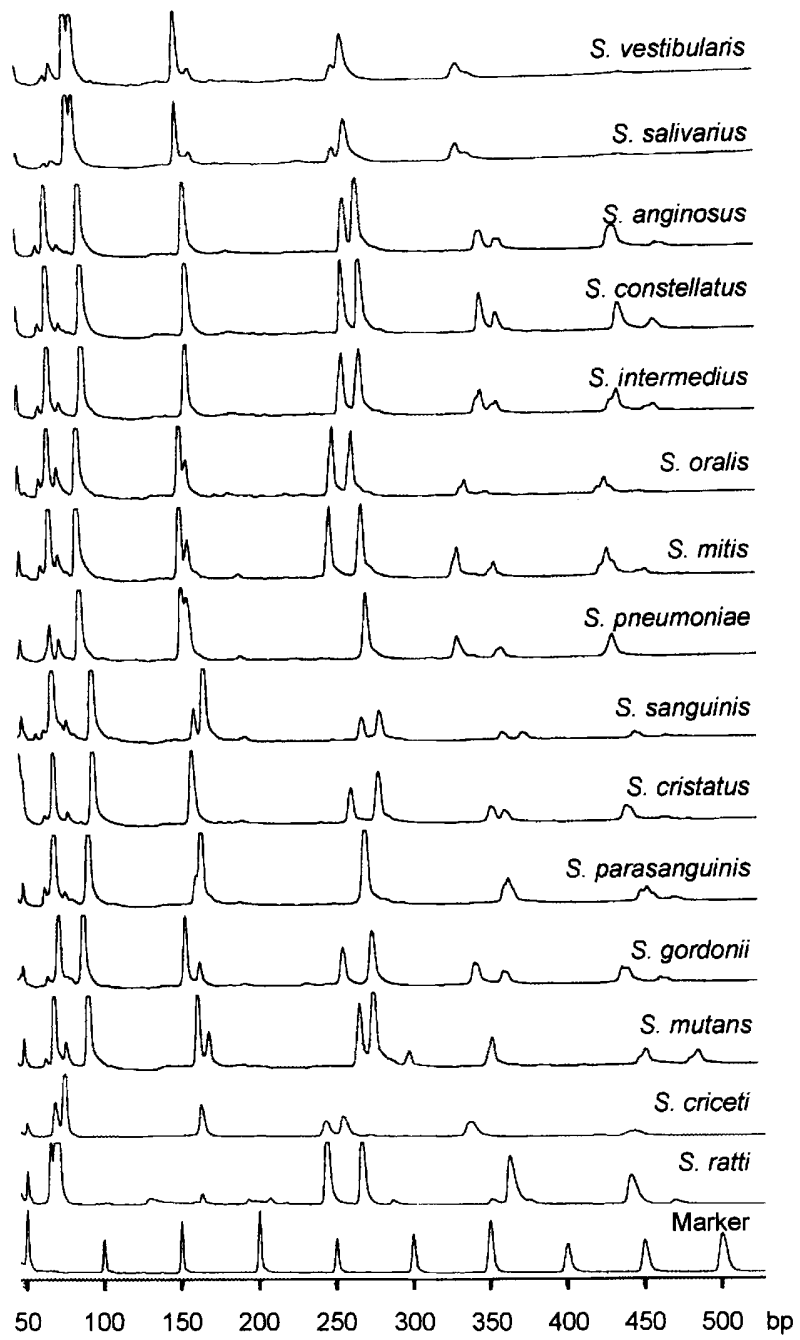

Fig. 1. Fluorescence densitogram of tDNA-ILP patterns of 15 type strains of clinically relevant viridans streptococci. The molecular mass marker was a 50-500 bp Cy5-labelled external standard.

the basis of these data, the threshold of pattern identity was defined as $91 \%$ similarity.

\section{Visual comparison of tDNA-ILP patterns}

Type and reference strains $(n=66)$ produced 16 distinct patterns of eight to twelve DNA fragments, which varied in size from 60 to $470 \mathrm{bp}$ (Table 1 and Figs 1-3). Easily distinguishable, species-specific patterns were produced by strains of $S$. cristatus, $S$. gordonii, $S$. oralis, $S$. mitis biovar $1, S$. pneumoniae, $S$. sanguinis, $S$. parasanguinis, $S$. anginosus, $S$. mutans, $S$. criceti and $S$. ratti. Indistinguishable patterns were obtained among two groups of species: $S$. vestibularis and $S$. salivarius on the one hand and $S$. constellatus and $S$. intermedius on the other (Fig. 1 and Table 1).

Reference strains of a given species produced patterns indistinguishable from the corresponding type strain, with the exception of $S$. mitis and S. pneumoniae. $S$.

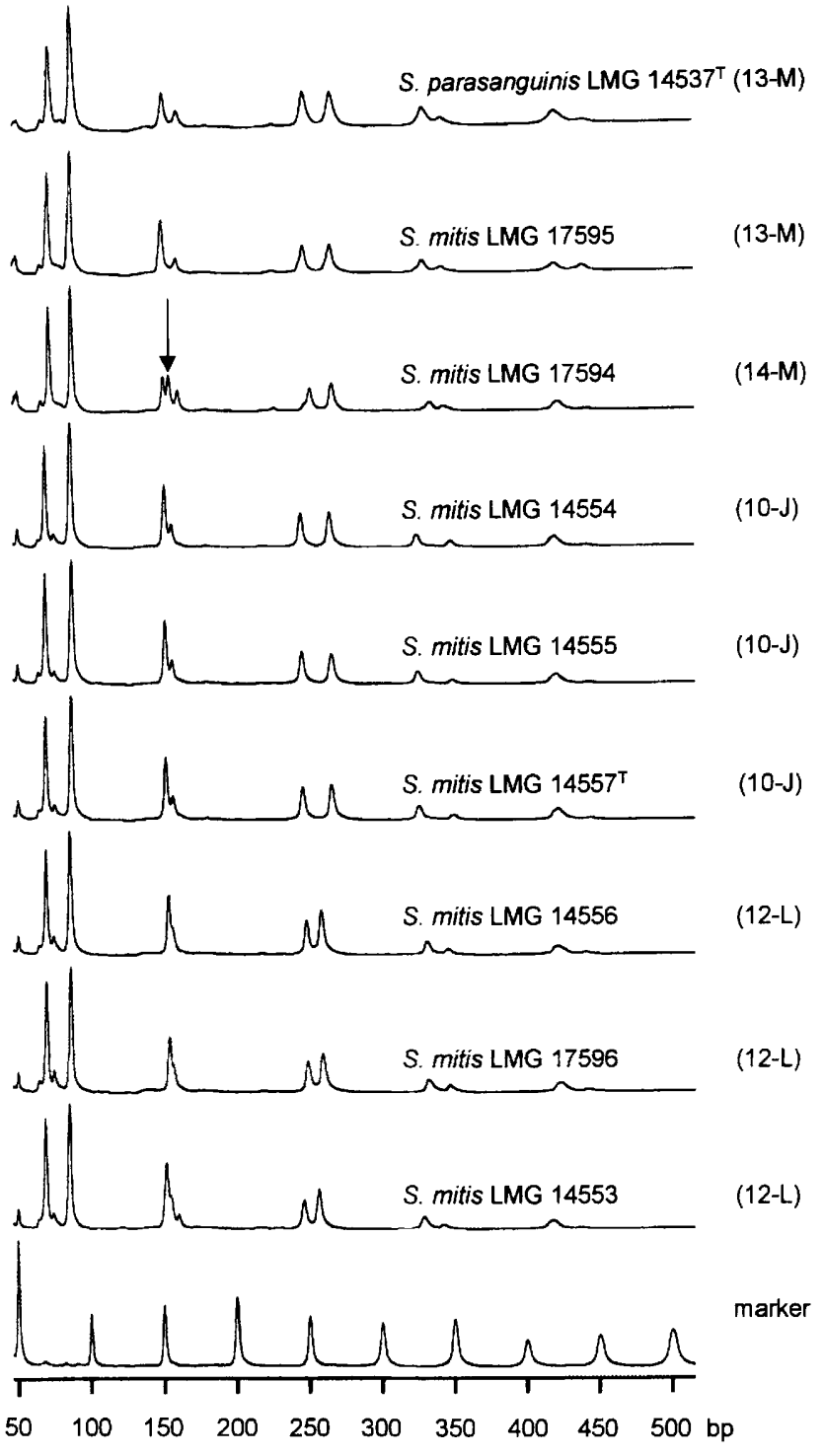

Fig. 2. Fluorescence densitogram of tDNA-ILP patterns of S. parasanguinis type strain and 5 . mitis strains. TDNA-ILP types are indicated in parentheses by numbers as defined by visual comparison and upper-case letters as defined by computer analysis. The arrow points to the additional peak of $153 \mathrm{bp}$ in S. mitis strain LMG 17594. Molecular mass marker as in Fig. 1.

mitis biovar 1 strains produced patterns identical to the type strain, whereas $S$. mitis biovar 2 strains produced patterns separated into two groups. The first group included two strains: S. mitis LMG 17595, which produced a tDNA-ILP pattern indistinguishable from the $S$. parasanguinis type strain, and LMG 17594, which produced a pattern that differed from the $S$. parasanguinis type strain pattern by the presence of an additional peak of $153 \mathrm{bp}$ (Fig. 2, arrow). The second group included three strains: $S$. mitis LMG 14556, LMG 17596 and LMG 14553, which produced common patterns, distinct from all others (Fig. 2). $S$. pneumoniae strains produced two patterns: strains LMG 14542 and ATCC 6301 produced identical 
Identification of viridans streptococci

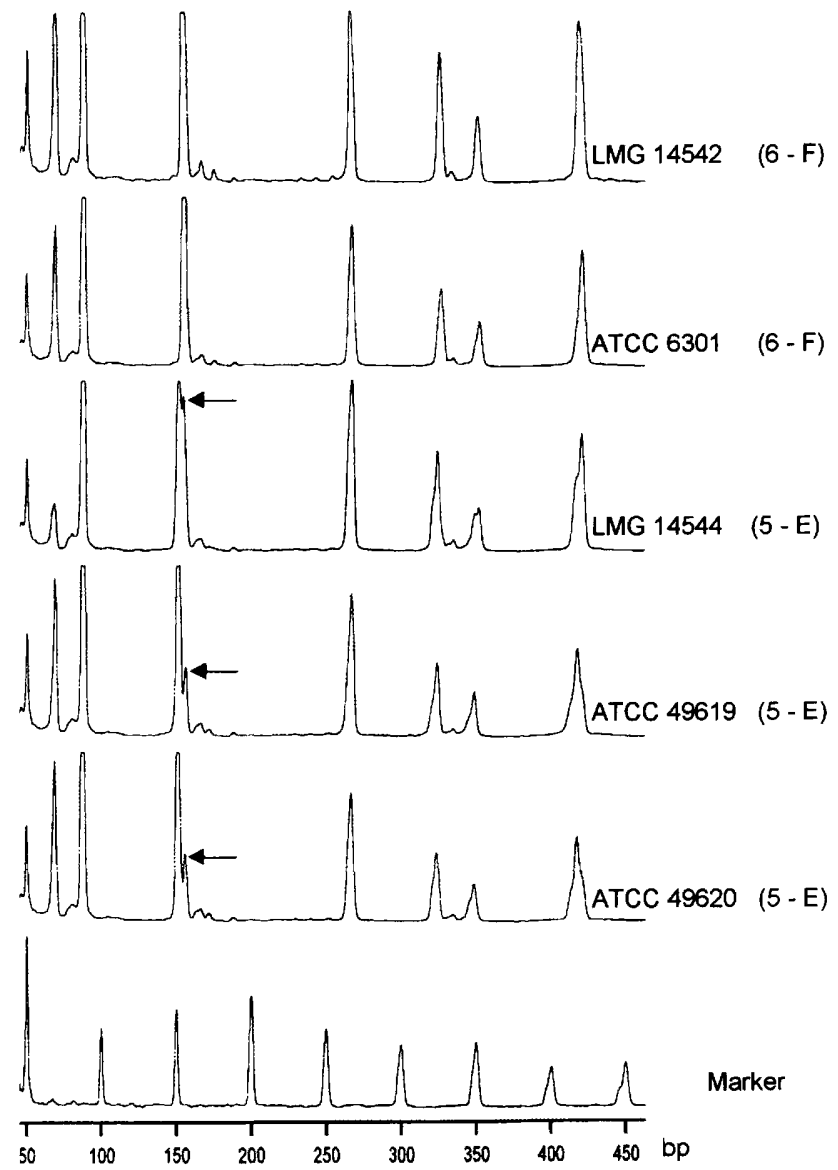

Fig. 3. Fluorescence densitogram of tDNA-ILP patterns of $S$. pneumoniae strains. TDNA-ILP types are indicated in parentheses as in Fig. 2. Horizontal arrows indicate an additional 156 bp peak in three strains. Molecular mass marker as in Fig. 1.

patterns, distinct from the pattern shared by strains LMG 14544, ATCC 49619 and ATCC 49620, which produced an additional peak of $156 \mathrm{bp}$ (Fig. 3, horizontal arrows).

\section{Computer-assisted analysis of tDNA-ILP patterns}

At the $91 \%$ similarity cut-off level, 15 clusters were obtained by comparison of the Pearson similarity coefficients of normalized tDNA-ILP patterns, which displayed between 30 and $99 \%$ similarity (Fig. 4). Reference and type strains within the same species clustered together at a mean of $95.4 \%$ (range $92-99 \%$ ) pattern similarity, except for $S$. pneumoniae and $S$. mitis strains. $S$. salivarius and $S$. vestibularis strains grouped in a single cluster, with $91 \%$ pattern similarity, as did $S$. constellatus and $S$. intermedius strains, with $92 \%$ similarity. These two latter species displayed $90 \%$ pattern similarity with $S$. anginosus strains, which were then grouped separately on the basis of this borderline value below the pattern identity level.

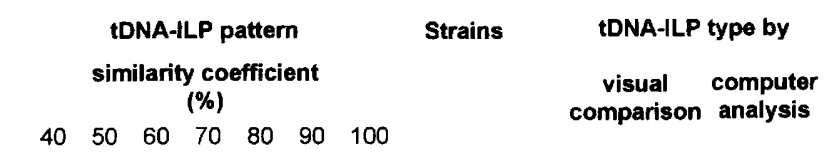

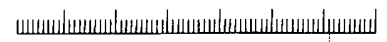
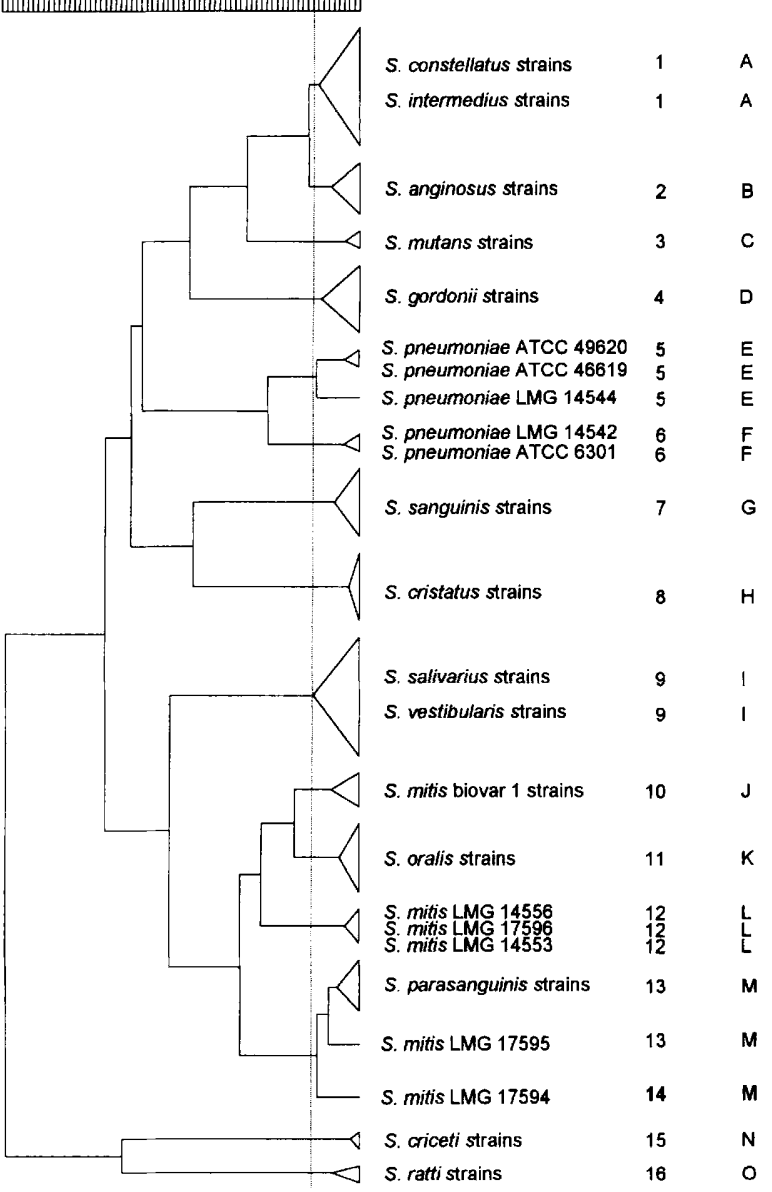

Fig. 4. Dendrogram of tDNA-ILP pattern relatedness of type and reference strains of viridans streptococci constructed by the UPGMA method. The threshold of pattern identity is indicated by a vertical dotted line. The minor discrepancy noted between visual and computer-assisted pattern clustering is indicated in bold type.

Only one minor discrepancy was noted between the visual and computer-assisted pattern clustering. $S$. mitis LMG 17594 was more than $91 \%$ similar to the $S$. parasanguinis cluster, whereas a minor additional DNA fragment (approximate size $153 \mathrm{bp}$ ) was observed by visual inspection (Fig. 2, arrow).

\section{DISCUSSION}

Identification of viridans streptococci to the species level is clinically relevant for several reasons. Firstly, certain species (e.g. S. anginosus, $S$. constellatus and $S$. intermedius) have been associated with different sites of infections (Hardie \& Whiley, 1994; Whiley et al., 1990). Secondly, antimicrobial susceptibility profiles vary among species (Hardie \& Whiley, 1994; Doern et al., 1996). For instance, strains of $S$. mitis are more frequently reported as penicillin resistant than other 
species of viridans streptococci. In the clinical laboratory, the currently available methods of identification of streptococci are based on phenotypic characters, including colonial morphology, growth characteristics and biochemical reactions, such as those assayed in the API Rapid ID32 Strep system (Coykendall, 1989; Hilman et al., 1989; Kilian et al., 1989; Tardif et al., 1989; Whiley et al., 1990; Beighton et al., 1991; Freney et al., 1992). However, intrinsic strain variability and overlapping characters between species frequently leads to equivocal results or inaccurate identification of certain species (Hilman et al., 1989; Kilian et al., 1989; Tardif et al., 1989). Strains of the anginosus and mitis groups are the most problematic in this regard (Coykendall, 1989; Kilian et al., 1989; Beighton et al., 1991; Freney et al., 1992).

Molecular methods have been developed for the identification of viridans streptococci to the species level (Rudney \& Larson, 1993; Ezaki et al., 1988; Jayarao et al., 1992; McClelland et al., 1992; Whiley et al., 1995; Garnier et al., 1997; Poyart et al., 1998; Vandamme et al., 1998). Among recently described genotypic techniques, size analysis of internal portions of the D-alanine: D-alanine ligase gene by PCR allowed the identification of $S$. mitis, $S$. gordonii, $S$. oralis, $S$. sanguinis, $S$. mutans and $S$. salivarius, and the distinction at the group level of strains of $S$. anginosus, $S$. constellatus and $S$. intermedius (Garnier et al., 1997). Sequence analysis of the superoxide dismutase gene enabled identification of strains of all species of viridans streptococci except for S. cristatus, which was not studied (Poyart et al., 1998). A molecular phenotypic method, electrophoresis of whole-organism proteins, differentiated most species among viridans streptococci except for strains of the anginosus group, which could not be distinguished (Vandamme et al., 1998). In addition, S. mitis biovar 2 strains were shown by this method to consist of several taxa.

In this study, we examined the usefulness of tDNAILP analysis, which has been proposed as a genotypic method for bacterial identification (Welsh \& McClelland, 1991, 1992; McClelland et al., 1992). These authors reported that this method allowed the distinction between species of staphylococci and streptococci, based on a limited sample of species and strains. In our study, we extended their findings by applying the method to the identification of 66 well-characterized viridans streptococcal strains belonging to 15 species, known to be clinically relevant and difficult to identify by conventional methods (Coykendall, 1989; Hardie \& Whiley, 1994; Hilman et al., 1989; Kilian et al., 1989; Tardif et al., 1989; Whiley et al., 1990; Beighton et al., 1991; Freney et al., 1992; Kawamura et al., 1995). Since tDNA spacers vary in size between species of a given genus by only a few base pairs (Vold, 1985; McClelland et al., 1992), we amplified these spacers using fluorescently labelled primers and analysed DNA fragments by PAGE on a DNA sequencer, as reported previously (Ehrenstein et al., 1996; Maes et al., 1997).

\section{The salivarius rRNA homology group}

Surprisingly, tDNA-ILP analysis could not distinguish between $S$. salivarius and $S$. vestibularis, two species of the salivarius rRNA homology group associated with human infection (Coykendall, 1989; Hardie \& Whiley, 1994; Whiley \& Hardie, 1988). This is in contrast with results reported with various methods, including DNA-DNA hybridization, biochemical tests (Whiley \& Hardie, 1988; Beighton et al., 1991; Freney et al., 1992), superoxide dismutase gene sequence determination (Poyart et al., 1998) and whole-cell protein electrophoretic analysis (Vandamme et al., 1998), which demonstrated unambiguously that these taxa represent two different species.

\section{The anginosus rRNA homology group}

There is an ongoing controversy among taxonomists who argue for and against the inclusion of organisms of this rRNA homology group into a single species, as described by Coykendall et al. (1987). The currently accepted subdivision into three species, $S$. anginosus, $S$. constellatus and $S$. intermedius, is supported by distinguishing phenotypic characteristics (Whiley \& Beighton, 1991), by clinical correlates such as distinct organ distribution of pyogenic infections (Whiley et al., 1990) and by sequence divergence of the superoxide dismutase gene (Poyart et al., 1998). On the other hand, whole-cell protein analysis (Vandamme et al., 1998) and sequence analysis of the $D$-alanine: $D$-alanine ligase gene (Garnier et al., 1997) showed this taxon to be homogeneous. In the present study, tDNA-ILP differentiated $S$. anginosus strains, by a minor variation only, from $S$. constellatus and $S$. intermedius, which showed a common pattern. Strains of all three species, however, clustered closely together. In contrast to our observation, minor variation in 16S-23S rRNA intergenic spacers distinguished $S$. constellatus from the two other species of this group (Whiley et al., 1995). This discrepancy illustrates the divergence between tRNA and rRNA gene organization, as described in Bacillus species (Vold, 1985).

\section{The mitis rRNA homology group}

Five of seven species in this group displayed speciesspecific tDNA-ILP patterns, irrespective of their biovar status (Table 1). Heterogeneous patterns were observed among $S$. pneumoniae strains, suggesting variation of tDNA gene organization. This is in contrast with superoxide dismutase gene sequence data, which showed that $S$. pneumoniae strains displayed the highest level of intraspecies sequence identity of all the species studied by Poyart et al. (1998). However, all $S$. pneumoniae strains could be identified correctly by tDNA-ILP analysis, as they clustered separately from all other taxa.

$S$. mitis strains showed an even more marked heterogeneity of tDNA-ILP patterns and were separated into three distantly related groups. Biovar 1 strains 
clustered in a separate group, close to the $S$. oralis cluster. Biovar 2 strains were subdivided into two groups: strains LMG 17594 and LMG 17595 clustered with $S$. parasanguinis, while strains LMG 14556, LMG 17596 and LMG 14553 produced a distinct pattern. In contrast, by whole-cell protein analysis, LMG 14556 was identified as a strain of S. cristatus and LMG 17594 as $S$. oralis, while LMG 17596 occupied a distinct position in the dendrogram (Vandamme et al., 1998). The nature of the discrepancies between tDNAILP analysis and whole-cell protein analysis is unknown. S. mitis biovar 2 strains were previously divided into two sub-groups on the basis of phenotypic characteristics by Kilian et al. (1989). These groups were the same as those observed for tDNA-ILP patterns with the exception of strain LMG 17594, which produced a tDNA-ILP pattern identical to that of $S$. parasanguinis. Interestingly, the need for further characterization of $S$. mitis biovar 2 strains was proposed by Kilian et al. (1989). We agree with this proposal and propose that whole-genome DNA-DNA hybridization would be needed in order to establish their correct identity.

\section{The mutans rRNA homology group}

The three species examined produced different patterns and could easily be distinguished from the other species, in agreement with the resolution provided by other molecular methods (Poyart et al., 1998; Vandamme et al., 1998).

\section{Comparison with phylogenetic data}

The topology of the phenogram of tDNA-ILP patterns above species level did not exhibit congruence with phylogenetic trees derived from sequences of $16 \mathrm{~S}$ rRNA genes (Bentley et al., 1991; Kawamura et al., 1995) and the superoxide dismutase gene (Poyart et al., 1998). This is not unexpected, and is presumably related to the small size of the genomic region examined for polymorphism by this assay. However, in another study of tDNA-ILP analysis of staphylococci, Maes et al. (1997) observed a congruence between the phenogram topology based on this assay and that of ribotype analysis.

\section{Conclusions}

PCR analysis of tDNA-ILP of reference strains of viridans streptococci known to be human pathogens revealed significant species homogeneity of tDNA gene organization and a high degree of interspecies heterogeneity, allowing the identification of 11 species at the species level and of four species at the rRNA homology group level. Observation of heterogeneous patterns in two species emphasizes the need to evaluate more than one reference strain of each species. The assay is rapid to perform and computer-assisted pattern analysis would allow easy classification of unknown strains. We conclude that this method should be evaluated on a large set of clinical isolates. The assay offers potential usefulness in the clinical laboratory, especially as a back-up method for the identification of problem strains that can not be identified by routine phenotypic tests, e.g. $S$. mitis and $S$. oralis strains.

\section{ACKNOWLEDGEMENTS}

This work was supported in part by a grant to Y.D. from the Fondation Erasme. P.V. is indebted to the Fund for Scientific Research-Flanders (Belgium) for a position as a post-doctoral research fellow. We thank N. Maes, A. Deplano, F. Brancart, E. Godfroid and C. Liesnard for technical advice and critical comments.

\section{REFERENCES}

Beighton, D., Hardie, J. M. \& Whiley, R. A. (1991). A scheme for the identification of viridans streptococci. J Med Microbiol 35, 367-372.

Bentley, R. W., Leigh, J. A. \& Collins, M. D. (1991). Intrageneric structure of Streptococcus based on comparative analysis of small-subunit rRNA sequences. Int J Syst Bacteriol 41, 487-494.

Carlsson, J. (1968). A numerical taxonomic study of human oral streptococci. Odontol Revy 19, 137-160.

Coykendall, A. L. (1977). Proposal to elevate the subspecies of Streptococcus mutans to species status, based on their molecular composition. Int J Syst Bacteriol 27, 26-30.

Coykendall, A. L. (1989). Classification and identification of the viridans streptococci. Clin Microbiol Rev 2, 315-328.

Coykendall, A. L., Wesbecher, P. M. \& Gustafson, K. B. (1987). 'Streptococcus milleri,' Streptococcus constellatus, and Streptococcus intermedius are later synonyms of Streptococcus anginosus. Int J Syst Bacteriol 37, 222-228.

Doern, G. V., Ferraro, M. J., Brueggemann, A. B. \& Ruoff, K. L. (1996). Emergence of high rates of antimicrobial resistance among viridans group streptococci in the United States. Antimicrob Agents Chemother 40, 891-894.

Ehrenstein, B., Bernards, A. T., Dijkshoorn, L., Gerner-Smidt, P., Towner, K. J., Bouvet, P. J., Daschner, F. D. \& Grundmann, H. (1996). Acinetobacter species identification by using tRNA spacer fingerprinting. J Clin Microbiol 34, 2414-2420.

Ezaki, T., Hashimoto, Y., Takeuchi, N., Yamamoto, H., Liu, S. L., Miura, H., Matsui, K. \& Yabuuchi, E. (1988). Simple genetic method to identify viridans group streptococci by colorimetric dot hybridization and fluorometric hybridization in microdilution wells. J Clin Microbiol 26, 1708-1713.

Freney, J., Bland, S., Etienne, J., Desmonceaux, M., Boeufgras, J. M. \& Fleurette, J. (1992). Description and evaluation of the semiautomated 4-hour rapid ID 32 Strep method for identification of streptococci and members of related genera. J Clin Microbiol 30, 2657-2661.

Garnier, F., Gerbaud, G., Courvalin, P. \& Galimand, M. (1997). Identification of clinically relevant viridans group streptococci to the species level by PCR. J Clin Microbiol 35, 2337-2341.

Handley, P., Coykendall, A., Beighton, D., Hardie, J. M. \& Whiley, R. A. (1991). Streptococcus crista sp. nov., a viridans streptococcus with tufted fibrils, isolated from the human oral cavity and throat. Int $J$ Syst Bacteriol 41, 543-547.

Hardie, J. M. \& Whiley, R. A. (1994). Recent developments in streptococcal taxonomy: their relation to infections. Rev Med Microbiol 5, 151-162. 
Hilman, J. D., Andrews, S. W., Painter, S. \& Stashenko, P. (1989). Adaptative changes in a strain of Streptococcus mutans during colonization of the human oral cavity. Microb Ecol Health Dis 2, 231-239.

Jayarao, B. M., Dore, J. J., Jr \& Oliver, S. P. (1992). Restriction fragment length polymorphism analysis of $16 \mathrm{~S}$ ribosomal DNA of Streptococcus and Enterococcus species of bovine origin. $J$ Clin Microbiol 30, 2235-2240.

Jorgensen, J. H., Doern, G. V., Ferraro, M. J., Knapp, C. C., Swenson, J. M. \& Washington, J. A. (1992). Multicenter evaluation of the use of Haemophilus test medium for broth microdilution antimicrobial susceptibility testing of Streptococcus pneumoniae and development of quality control limits. $J$ Clin Microbiol 30, 961-966.

Kawamura, Y., Hou, X.-G., Sultana, F., Miura, H. \& Ezaki, T. (1995). Determination of 16S rRNA sequences of Streptococcus mitis and Streptococcus gordonii and phylogenetic relationships among members of the genus Streptococcus. Int J Syst Bacteriol 45, 406-408.

Kilian, M., Mikkelsen, L. \& Henrichsen, J. (1989). Taxonomic study of viridans streptococci: description of Streptococcus gordonii sp. nov. and emended descriptions of Streptococcus sanguis (White and Niven 1946), Streptococcus oralis (Bridge and Sneath 1982), and Streptococcus mitis (Andrewes and Horder 1906). Int J Syst Bacteriol 39, 471-484.

McClelland, M., Petersen, C. \& Welsh, J. (1992). Length polymorphisms in tRNA intergenic spacers detected by using the polymerase chain reaction can distinguish streptococcal strains and species. J Clin Microbiol 30, 1499-1504.

Maes, N., De Gheldre, Y., De Ryck, R., Vaneechoutte, M., Meugnier, H., Etienne, J. \& Struelens, M. J. (1997). Rapid and accurate identification of Staphylococcus species by tRNA intergenic spacer length polymorphism analysis. J Clin Microbiol 35, 2477-2481.

Pitcher, D. G., Saunders, N. A. \& Owen, R. J. (1989). Rapid extraction of bacterial genomic DNA with guanidium thiocyanate. Lett Appl Microbiol 8, 151-156.

Poyart, C., Quesne, G., Coulson, S., Berche, P. \& Trieu-Cuot, P. (1998). Identification of streptococci to species level by sequencing the gene encoding the manganese-dependent superoxide dismutase. $J$ Clin Microbiol 36, 41-47.
Rudney, J. D. \& Larson, C. J. (1993). Species identification of oral viridans streptococci by restriction fragment polymorphism analysis of rRNA genes. J Clin Microbiol 31, 2467-2473.

Tardif, G., Sulavik, M. C., Jones, G. W. \& Clewell, D. B. (1989). Spontaneous switching of the sucrose-promoted colony phenotype in Streptococcus sanguis. Infect Immun 57, 3945-3948.

Vandamme, P., Torck, U., Falsen, E., Pot, B., Goossens, H. \& Kersters, K. (1998). Whole-cell protein electrophoretic analysis of viridans streptococci: evidence for heterogeneity among Streptococcus mitis biovars. Int J Syst Bacteriol 48, 117-125.

Vaneechoutte, M., Boerlin, P., Tichy, H.-V., Bannerman, E., Jäger, B. \& Bille, J. (1998). Comparison of PCR-based DNA fingerprinting techniques for the identification of Listeria species and their use for atypical Listeria isolates. Int J Syst Bacteriol 48, $127-139$

Vold, B. S. (1985). Structure and organization of genes for transfer ribonucleic acid in Bacillus subtilis. Microbiol Rev 49, 71-80.

Welsh, J. \& McClelland, M. (1991). Genomic fingerprints produced by PCR with consensus tRNA gene primers. Nucleic Acids Res 19, 861-866.

Welsh, J. \& McClelland, M. (1992). PCR-amplified length polymorphisms in tRNA intergenic spacers for categorizing staphylococci. Mol Microbiol 6, 1673-1680

Whiley, R. A. \& Beighton, D. (1991). Emended descriptions and recognition of Streptococcus constellatus, Streptococcus intermedius, and Streptococcus anginosus as distinct species. Int $J$ Syst Bacteriol 41, 1-5.

Whiley, R. A. \& Hardie, J. M. (1988). Streptococcus vestibularis $\mathrm{sp.}$ nov. from the human oral cavity. Int J Syst Bacteriol 38, 335-339.

Whiley, R. A., Fraser, H., Hardie, J. M. \& Beighton, D. (1990). Phenotypic differentiation of Streptococcus intermedius, Streptococcus constellatus, and Streptococcus anginosus within the 'Streptococcus milleri group'. J Clin Microbiol 28, 1497-1501.

Whiley, R. A., Duke, B., Hardie, J. M. \& Hall, L. M. C. (1995). Heterogeneity among 16S-23S rRNA intergenic spacers of species within the 'Streptococcus milleri group'. Microbiology 141, 1461-1467. 